\title{
RESEARCH
}

Open Access

\section{Non-invasive imaging reveals conditions that impact distribution and persistence of cells after in vivo administration}

Lauren Scarfe ${ }^{1,2+}$, Arthur Taylor ${ }^{1,2 \dagger}$, Jack Sharkey ${ }^{1,2+}$, Rachel Harwood ${ }^{1,2}$, Michael Barrow ${ }^{4}$, Joan Comenge ${ }^{5}$, Lydia Beeken ${ }^{1}$, Cai Astley ${ }^{1}$, Ilaria Santeramo ${ }^{1,2}$, Claire Hutchinson ${ }^{3}$, Lorenzo Ressel $^{6}$, Jon Smythe ${ }^{7}$, Eric Austin, Raphael Levy ${ }^{5}$, Matthew J. Rosseinsky ${ }^{4}$, Dave J. Adams ${ }^{8}$, Harish Poptani ${ }^{1,2}$, Brian K. Park ${ }^{3}$, Patricia Murray ${ }^{1,2,9^{*}}$ and Bettina Wilm ${ }^{1,2,9^{*}}$

\begin{abstract}
Background: Cell-based regenerative medicine therapies are now frequently tested in clinical trials. In many conditions, cell therapies are administered systemically, but there is little understanding of their fate, and adverse events are often under-reported. Currently, it is only possible to assess safety and fate of cell therapies in preclinical studies, specifically by monitoring animals longitudinally using multi-modal imaging approaches. Here, using a suite of in vivo imaging modalities to explore the fate of a range of human and murine cells, we investigate how route of administration, cell type and host immune status affect the fate of administered cells.

Methods: We applied a unique imaging platform combining bioluminescence, optoacoustic and magnetic resonance imaging modalities to assess the safety of different human and murine cell types by following their biodistribution and persistence in mice following administration into the venous or arterial system.

Results: Longitudinal imaging analyses (i) suggested that the intra-arterial route may be more hazardous than intravenous administration for certain cell types, (ii) revealed that the potential of a mouse mesenchymal stem/ stromal cell (MSC) line to form tumours depended on administration route and mouse strain and (iii) indicated that clinically tested human umbilical cord (hUC)-derived MSCs can transiently and unexpectedly proliferate when administered intravenously to mice.

Conclusions: In order to perform an adequate safety assessment of potential cell-based therapies, a thorough understanding of cell biodistribution and fate post administration is required. The non-invasive imaging platform used here can expose not only the general organ distribution of these therapies, but also a detailed view of their presence within different organs and, importantly, tumourigenic potential. Our observation that the hUC-MSCS but not the human bone marrow (hBM)-derived MSCs persisted for a period in some animals suggests that therapies with these cells should proceed with caution.
\end{abstract}

Keywords: Cell therapies, Mesenchymal stem/stromal cells, Safety, Preclinical models, Cell tracking, Multi-modal imaging

\footnotetext{
* Correspondence: P.A.Murray@liverpool.ac.uk; bwilm@liverpool.ac.uk Patricia Murray and Bettina Wilm are joint seniors.

Lauren Scarfe, Arthur Taylor and Jack Sharkey contributed equally.

'Department of Cellular and Molecular Physiology, University of Liverpool,

Liverpool, UK

Full list of author information is available at the end of the article
}

(c) The Author(s). 2018 Open Access This article is distributed under the terms of the Creative Commons Attribution 4.0 International License (http://creativecommons.org/licenses/by/4.0/), which permits unrestricted use, distribution, and reproduction in any medium, provided you give appropriate credit to the original author(s) and the source, provide a link to the Creative Commons license, and indicate if changes were made. The Creative Commons Public Domain Dedication waiver (http://creativecommons.org/publicdomain/zero/1.0/) applies to the data made available in this article, unless otherwise stated. 


\section{Background}

In recent years, biomedical and translational research has focussed on exploring the potential of regenerative medicine therapies (RMTs) to treat a vast number of diseases [1]. A primary safety concern of RMTs, especially if based on stem cells, is their potential to form tumours, due to their proliferative and multi-potential differentiation characteristics [2].

Mesenchymal stem/stromal cells (MSCs) isolated from bone marrow, adipose tissue or umbilical cord are being tested in clinical trials for a range of conditions, but in many cases, preclinical safety data are not available, and the authors fail to report whether the cells cause any adverse effects. Bone marrow-derived (hBM)-MSCs have been used for many years and appear safe [3], but a review of adipose-derived MSCs concluded that while adverse events are rare, they nevertheless do occur and are likely to be related to underlying health conditions of the patients or administration route [4]. Human umbilical cord-derived (hUC)-MSCs have only recently been introduced in clinical trials, with more than $50 \%$ of these initiated within the last 3 years (a summary of registered trials is presented in Additional file 1). hUC-MSCs are less immunogenic than other types of MSCs, which contributes to their attraction as clinical RMTs. However, because of their low immunogenicity in combination with higher proliferative behaviour, these cells may also pose a greater potential risk [5]. Yet until now, their safety profile has not been robustly assessed. The importance of preclinical safety testing is highlighted by a recent report where a tumour developed in a patient's spinal cord following intrathecal administration of stem cells [6].

Assessing the safety of cell therapies by tracking their distribution and fate over time after administration can be achieved in preclinical models. Many animal studies use lipophilic membrane dyes, such as PKH26 or CM-Dil, to label the cells, which requires culling of animals at various time points and histological analysis [711]. The key flaws of this approach are (1) the detection of false-positive cells because lipophilic dyes have the potential to transfer to host cells [12]; (2) very large animal numbers, infringing on the principles of the 3Rs (Replacement, Reduction, Refinement); and (3) the failure to longitudinally monitor the cell fate in each individual animal over time. By contrast, non-invasive imaging technologies have opened up exciting new possibilities for preclinical assessment of the safety of cell therapies by allowing longitudinal in vivo cell tracking to monitor cell biodistribution and persistence. Preclinical imaging technologies for cell tracking, some of which have clinical relevance, include magnetic resonance imaging (MRI) to detect cells labelled with superparamagnetic iron oxide nanoparticles (SPIONs), multispectral optoacoustic tomography (MSOT) to detect cells labelled with gold nanorods (GNRs) or near-infrared red fluorescent protein [13-17] and bioluminescence imaging (BLI) for the detection of cells expressing the genetic reporter, firefly luciferase [18-20]. Genetic reporters are particularly advantageous because signals are only generated from living cells, thus allowing the monitoring of cell proliferation and tumour growth and avoiding problems based on nanoparticle dissociation from cells, which can lead to false-positive signals. However, the spatial resolution of BLI is poor, making it difficult to precisely locate the cells [18]. By contrast, both preclinical MSOT and MRI have much higher spatial resolution (150 $\mu \mathrm{m}$ and $50 \mu \mathrm{m}$, respectively), providing details of the inter- and intra-organ distribution of administered cells. Moreover, as MRI is routinely used in the clinic, it provides a bridge for preclinical and clinical studies.

An advanced approach to longitudinal in vivo cell tracking is the use of multi-modal imaging strategies that combine cell labels and reporters, including dual-labelling with both the luciferase reporter gene for BLI, and either gold nanorods (GNRs) for photoacoustic imaging [21-24] or superparamagnetic iron oxide nanoparticles (SPIONs) for MRI [25-28]. Such multi-modal imaging approaches benefit from the sensitivity of the luciferase-based signal conferred by living cells, in combination with the high resolution of MRI and photoacoustic imaging systems to detect the nanoparticles inside organs, allowing a comprehensive longitudinal analysis of cell fate and safety risks.

The most common way to administer cells systemically in small animals is via the intravenous (IV) route through the tail vein [29], delivering cells directly to the lungs where they are sequestered as a consequence of the pulmonary first-pass effect [30-35]. Previous reports have suggested that IV-administered cells labelled with lipophilic dyes bypass the lungs, but this is likely due to false-positive staining. For example, in renal regenerative studies, PKH26 dye-labelled IV-administered cells have been reported to engraft in injured kidneys and replace damaged renal cells [9-11, 36], but a more recent study using this lipophilic dye in combination with GFP expression shows that while the dye can sometimes be detected in the kidneys, the cells remain trapped in the lungs [32]. These recent findings are corroborated by in vivo cell tracking studies which show that after IV injection, transplanted cells predominantly accumulate in the lungs [19, 33, 34], fail to integrate or differentiate into tissue-specific cell types and disappear within 7 days [19, 20, 37].

Although the IV route is also frequently used in clinical trials, administration via the arterial circulation is not uncommon. For instance, clinical trials testing the potential of cell therapies to treat myocardial infarction 
administer cells into the coronary arteries or left cardiac ventricle [24,38], while in patients with peripheral artery disease or stroke, intra-arterial injection via the femoral or carotid artery, respectively, is frequently employed [39]. Intra-arterial administration will also lead to systemic distribution to other organs, including the brain, and cells passing through the blood-brain barrier could pose an important safety concern. However, a detailed analysis of cell fate after intra-arterial cell administration has so far not been reported [4].

Here, we have implemented a multi-modal imaging approach comprising BLI, MSOT and MRI, to assess biodistribution and fate of different cell types following venous and arterial administration in healthy mice. Some of these cell types are currently being used in clinical trials, including hUC-MSCs (Additional file 1), hBM-MSCs [40], kidney-derived cells [41] and macrophages [42]. We show that our multi-modal imaging approach allows us to determine the immediate distribution of the cells with respect to the route of administration, and to assess the long-term fate of mouse and human MSCs, and their propensity to form tumours. Our findings demonstrate that the multi-modal imaging platform allowing longitudinal cell tracking is an important tool to identify safety concerns of cells used in clinical trials.

\section{Methods}

\section{Animals}

Mice (Charles River, UK) were housed in individually ventilated cages under a 12-h light/dark cycle, with ad libitum access to standard food and water. All animal experiments were performed under a licence granted under the UK Animals (Scientific Procedures) Act 1986 and were approved by the University of Liverpool ethics committee. Experiments are reported in line with the ARRIVE guidelines. Tumour formation was closely monitored, and the tumour burden was not allowed to exceed the recommended size [43].

\section{Cell preparation}

Mouse kidney-derived stem cells (mKSCs) [44], the D1 mouse MSC (mMSC) line (D1 ORL UVA [D1](ATCC ${ }^{\circ}$ CRL-12424 $\left.4^{\mathrm{m}}\right)$ ), primary human umbilical cord-derived MSCs (hUC-MSCs; collected from consenting donors and produced identically to those already being used in clinical trials by NHS Blood and Transplant (NHSBT)), primary human bone marrow-derived MSCs (hBM-MSCs; Lonza PT-2501), human kidney cells (hKCs; the kidneys deemed unsuitable for transplantation via UK NHSBT [32]) and RAW264.7 macrophages (European Collection of Authenticated Cell Cultures 91062702) were cultured at $37^{\circ} \mathrm{C}$ under a humidified atmosphere with $5 \% \mathrm{CO}_{2}$ (culture media are described in Additional file 2). Primary human cells were used up to passage 8 , whereas mouse lines were cultured up to passage 25.

For detection by BLI, cells were transduced with a lentiviral vector encoding either firefly luciferase (Luc) or a bicistronic construct of Luc and ZsGreen, all under control of the constitutive promoter EF1a. The vector plasmids were a gift from Bryan Welm (Addgene plasmids \# 21375 and 39196), and the production of viral particles and cell transduction was carried out as previously described $[45,46]$. The mKSCs were infected with a multiplicity of infection (MOI) of 10, whereas all other cells were infected with an MOI of 5 . At least $90 \%$ of the cell populations expressed the vector after transduction, except for macrophages, which did not tolerate polybrene and thus displayed a reduced infection efficiency. Cell sorting based on ZsGreen fluorescence obtained a macrophage population that was $100 \%$ positive for the luciferase construct. Cells for karyotyping were treated with colcemid $(0.1 \mu \mathrm{g} /$ $\mathrm{mL}$ ) followed by a hypotonic treatment and fixation in Carnoy's fixative. Chromosome analyses were carried out by cytogenetics specialists (CellGS, Cambridge, UK).

Average cell diameter was estimated by measuring the volume of a cell pellet in a packed cell volume (PCV) tube according to the manufacturer's instructions (Techno Plastic Products, Switzerland). The cell diameter was calculated using the formula:

$$
\varnothing_{\text {cell }}=2 \times \sqrt[3]{\frac{3\left(\frac{V}{c}\right)}{4 \pi}}
$$

where $V$ corresponds to the pellet volume and $c$ to the number of cells in the pellet.

For MR tracking, cells were labelled with diethylaminoethyl-dextran-coated SPIONs synthesised in house as previously described $[25,26]$. SPIONs were added to the culture medium at a concentration of $25 \mu \mathrm{g}[\mathrm{Fe}] / \mathrm{mL}$ $24 \mathrm{~h}$ prior to the experiment, after which cells were washed to remove excess particles and harvested for administration as described below. This resulted in an iron content of $\sim 6 \mathrm{pg}[\mathrm{Fe}] / \mathrm{cell}$.

GNRs were synthesised using a protocol first reported by El-Sayed's group [47] and coated with silica as described by Comenge et al. [23]. Macrophages were labelled for $24 \mathrm{~h}$ with GNRs at a final concentration of 10 pM before harvesting for cell injection. Neither of the labelling approaches (SPIONs/GNRs) caused any reduction in cell viability.

\section{Cell administration}

Cells were trypsinised, pelleted and resuspended in ice-cold phosphate-buffered saline (PBS) and kept on ice until injection. One hundred microlitres of cell suspension was administered to mice via intravenous (IV) or 
ultrasound-guided intracardiac (IC) injection. A description and comments on this method of administration are provided in Additional file 3. Tolerance of dosing of cells was adjusted in separate experiments.

\section{Bioluminescence imaging}

For short-term studies, ZsGreen ${ }^{+} / \mathrm{Luc}^{+}$mMSCs, mKSCs, hKCs, macrophages or $\mathrm{Luc}^{+}$hUC-MSCs and hBM-MSCs were administered IV or IC to BALB/c mice. For long-term study, ZsGreen ${ }^{+} / \mathrm{Luc}^{+} \mathrm{mMSCs}$ or $\mathrm{Luc}^{+}$hUC-MSCs were administered IV or IC to BALB/c (severe combined immunodeficient) SCID mice (see Table 1 for route, cell dose and number of animals in each experiment). The in vivo biodistribution of cells was monitored by BLI immediately after cell administration and at multiple time points up to 30 days. Mice were administered $150 \mathrm{mg} / \mathrm{kg}$ body weight luciferin (Promega, UK) subcutaneously and imaged 15 min later in a bioluminescence imager (IVIS Spectrum, Perkin Elmer, UK). Imaging data were normalised to the acquisition conditions and expressed as radiance (photons/second/ $\mathrm{cm}^{2} /$ steradian $\left.\left(\mathrm{p} / \mathrm{s} / \mathrm{cm}^{2} / \mathrm{sr}\right)\right)$, and the colour scale was adjusted according to the strength of signal detected. Because IV injections into the tail can lead to a small fraction of cells remaining in or around the injection site, causing strong signal intensities, the tails of animals that received cells via this route were covered prior to data acquisition. At the respective study end points, mice were culled and organs with any visibly identifiable tumours imaged ex vivo by BLI. Kidneys were cut coronally for ex vivo imaging, and all other organs were imaged whole. Bioluminescence signals of whole live mice or individual organs ex vivo were quantified by drawing regions of interest (ROIs) from which the total flux (photons/second) was obtained. The relative signal intensity from each organ was calculated as a percentage of the signal intensity from all organs. For ex vivo kidney imaging, the ROI was drawn around all four kidney halves and a single value for total bioluminescence signal was recorded.

\section{Multispectral optoacoustic tomography (MSOT)}

MSOT was carried out using the inVision 256-TF MSOT imaging system (iThera Medical, Germany). Images were recorded at the following wavelengths: every $10 \mathrm{~nm}$ from $660 \mathrm{~nm}$ and $760 \mathrm{~nm}$ and every $20 \mathrm{~nm}$ from $780 \mathrm{~nm}$ and $900 \mathrm{~nm}$, at a rate of 10 frames per second and averaging 10 consecutive frames. All mice were allowed to equilibrate in the imaging system for $15 \mathrm{~min}$ prior to recording data. For monitoring of the biodistribution of macrophages after IV administration, a $15-\mathrm{mm}$ section of the abdomen to include the liver, kidneys and spleen of the mice was imaged repeatedly for a total of $4.5 \mathrm{~h}$; $30 \mathrm{~min}$ into the imaging, the mice received the macrophages via a tail vein catheter. For the IC imaging,

Table 1 Experimental details of studies, mouse strains, cell types, route of administration, dose and number of animals studied

\begin{tabular}{|c|c|c|c|c|c|}
\hline Study & Mouse strain & Cell type & Route & Dose & Number of animals \\
\hline \multirow{6}{*}{$\begin{array}{l}\text { BLI short-term biodistribution } \\
\text { (and MSOT for RAW macrophages) }\end{array}$} & $\mathrm{BALB} / \mathrm{C}$ & $\mathrm{mMSC}$ & IV and IC & $1.0 \times 10^{6}$ & \multirow{6}{*}{$\begin{array}{l}\text { Minimum } n=3 \text { for each cell } \\
\text { type and administration route }\end{array}$} \\
\hline & $\mathrm{BALB} / \mathrm{C}$ & $\mathrm{mKSC}$ & IV and IC & $1.0 \times 10^{6}$ & \\
\hline & $\mathrm{BALB} / \mathrm{C}$ & hUC-MSC & IV and IC & $1.0 \times 10^{6}$ & \\
\hline & $\mathrm{BALB} / \mathrm{C}$ & hBM-MSC & IV and IC & $5.0 \times 10^{5}$ & \\
\hline & $\mathrm{BALB} / \mathrm{C}$ & hKC & IV and IC & $0.3 \times 10^{5}$ & \\
\hline & $\mathrm{BALB} / \mathrm{C}$ & Macrophages & IV and IC & $1.0 \times 10^{7}$ & \\
\hline \multirow[t]{11}{*}{ BLI long-term biodistribution } & $\mathrm{BALB} / \mathrm{C} \mathrm{SCID}$ & mMSC & IV & $1.0 \times 10^{6}$ & $n=3$ \\
\hline & BALB/C SCID & mMSC & IC & $1.0 \times 10^{6}$ & $n=5$ \\
\hline & $\mathrm{BALB} / \mathrm{C}$ & mMSC & IC & $1.0 \times 10^{6}$ & $n=4$ \\
\hline & FVB & mMSC & IC & $1.0 \times 10^{6}$ & $n=4$ \\
\hline & MF1 & $\mathrm{mMSC}$ & IC & $1.0 \times 10^{6}$ & $n=4$ \\
\hline & $\mathrm{BALB} / \mathrm{C} \mathrm{SCID}$ & hUC-MSC & IV & $1.0 \times 10^{6}$ & $n=13$ \\
\hline & $\mathrm{BALB} / \mathrm{C} \mathrm{SCID}$ & hUC-MSC & IC & $1.0 \times 10^{6}$ & $n=3$ \\
\hline & BALB/c SCID & hUC-MSC & IV & $5.0 \times 10^{5}$ & $n=6$ \\
\hline & $\mathrm{BALB} / \mathrm{C} \mathrm{SCID}$ & hUC-MSC & IC & $5.0 \times 10^{5}$ & $n=14$ \\
\hline & BALB/C SCID & hBM-MSC & IV & $5.0 \times 10^{5}$ & $n=6$ \\
\hline & BALB/C SCID & hBM-MSC & IC & $5.0 \times 10^{5}$ & $n=6$ \\
\hline \multirow[t]{2}{*}{ MRI cell tracking } & $\mathrm{BALB} / \mathrm{C}$ & $\mathrm{mMSC}$ & IV & $1.0 \times 10^{6}$ & $n=2$ \\
\hline & $\mathrm{BALB} / \mathrm{C}$ & mMSC & IC & $1.0 \times 10^{6}$ & $n=7$ \\
\hline
\end{tabular}

Cell numbers for IC administration had to be individually optimised for each cell type used since mice responded severely to higher numbers of some of the cell types after injection into the left ventricle. Administered cell numbers caused no health problems after IV injection in any of the cell types used 
a $15-\mathrm{mm}$ section of the abdomen was imaged once, followed by an ultrasound (Prospect 2.0, S-Sharp, Taiwan)-guided injection of macrophages into the left ventricle of the heart. Mice were then returned to the photoacoustic imaging system for imaging as previously described. Data was reconstructed, and multispectral processing was performed to resolve signals in the liver, kidney and spleen for GNRs. Regions of interest were drawn around the liver, right kidney and spleen (an example is shown in Additional file 4) to generate mean pixel intensity data.

\section{MR imaging}

ZsGreen ${ }^{+} / \mathrm{Luc}^{+} / \mathrm{SPION}^{+}$mMSCs $\left(10^{6}\right)$ were administered to BALB/c mice IV $(n=2)$ or IC $(n=2$ for short-term analysis; $n=5$ for longitudinal tracking). The biodistribution of cells in the brain and abdomen was imaged with a Bruker Avance III spectrometer interfaced to a 9.4 $\mathrm{T}$ magnet system (Bruker Biospec 90/20 USR) using a Fast Low-Angle Shot (FLASH) $\mathrm{T}_{2}{ }^{*}$-weighted sequence at baseline and up to 2 days post administration. $T_{2}$ " relaxation times were obtained from $\mathrm{a} \mathrm{T}_{2}{ }^{*}$ map generated with a multi-gradient echo sequence by drawing ROIs around the cortex of the kidney (an example is shown in Additional file 5) or a region of the liver. At least one animal was culled at each time point for histological analyses, and brains and kidneys were fixed with $4 \%$ formaldehyde and imaged at a higher resolution post mortem (all MRI acquisition parameters are described in the Additional file 6). Tumours were imaged with a $\mathrm{T}_{2}$-weighted fast spin echo sequence.

\section{Histopathological analysis}

Perfusion-fixed frozen brain and kidney sections were stained for the endothelial cell marker isolectin B4 (IB4, L2140, Sigma Aldrich, UK) as described previously [48]. The presence of $\mathrm{ZsGreen}^{+}$mMSCs within the brain and glomerular capillaries was imaged by confocal microscopy (LSM 800 Airyscan, Zeiss, Germany). Frozen kidney sections $(7 \mu \mathrm{m})$ were stained for the presence of iron (Iron Stain Kit, Sigma, UK) according to the manufacturer's instructions to detect SPIONs, and consecutive sections were counterstained with DAPI. Prussian blue-stained cells and ZsGreen-positive mMSCs were imaged by bright field and epifluorescence microscopy.

Tumours were fixed in $4 \%$ paraformaldehyde at $4{ }^{\circ} \mathrm{C}$ for $24 \mathrm{~h}$, washed in PBS and processed through an ethanol and xylene series before embedding in paraffin. Five-micrometre tissue sections were stained for haematoxylin and eosin (H\&E) by standard methods and morphologically assessed.

\section{Fluorescence-activated cell sorting (FACS)}

The bone marrow was extracted as previously described [49]. In short, the femurs and tibias were collected in
PBS containing penicillin/streptomycin; the bone marrow was flushed out with PBS, centrifuged ( $400 g, 5 \mathrm{~min})$ and then resuspended in fresh PBS before analysis by flow cytometry for ZsGreen expression.

\section{Statistical analyses}

Statistical analyses were performed using Minitab 17 statistical software. A one-way analysis of variance (ANOVA) was used to compare multiple groups. When an ANOVA resulted in a statistically significant result $(p$ $<0.05$ ), a Tukey pairwise comparison was performed in order to determine which groups were significantly different. The Tukey pairwise comparison assigned each group at least one letter, and groups that did not share a letter were significantly different from one another.

\section{Results}

Whole-body biodistribution of different cell types

following intravenous (IV) and intracardiac (IC) administration

Bioluminescence imaging showed that IV delivery of ZsGreen ${ }^{+} / \mathrm{Luc}^{+}$mouse MSCs (mMSCs), mouse kidney-derived stem cells (mKSCs) and human kidney cells (hKCs) resulted in signals exclusively in the lungs, while signals from IV-administered macrophages were also located more posteriorly (Fig. 1a). This was expected because macrophages are known to traverse the lungs and populate other organs, such as the liver and spleen. In contrast, intra-arterial delivery via the left cardiac ventricle (from now on referred to as intracardiac (IC)) resulted in a whole-body distribution of all cell types (Fig. 1a).

Organ-specific ex vivo imaging within $1 \mathrm{~h}$ of IV administration of mKSCs confirmed that the signal was limited to the lungs (Fig. 1b, d). In contrast, after IC administration, bioluminescent signals were detected in the brain, heart, lungs, kidney, spleen and liver (Fig. 1a). IV-administered macrophages were found predominantly within the lungs by ex vivo imaging (Fig. 1c), but weaker signals were also detected in the spleen and liver, kidneys and brain, confirming the in vivo signal distribution. Ex vivo analysis of macrophages after IC injection showed signals in most organs that were imaged (Fig. 1c, e).

To monitor the temporal dynamics of macrophage migration, cells were labelled with GNRs, injected IV and monitored continuously for $4.5 \mathrm{~h}$ using MSOT. Signal intensity began to increase immediately in both the liver and spleen until around $90 \mathrm{~min}$ when it started to plateau (Fig. 1f), but remained close to basal levels in the kidney, consistent with BLI ex vivo analysis (Fig. 1e, f). However, when GNR-labelled macrophages were administered IC, increases in signal intensity in the kidney were comparable to those in the liver and spleen $4 \mathrm{~h}$ post administration (quantification is shown in Additional file 4c). 


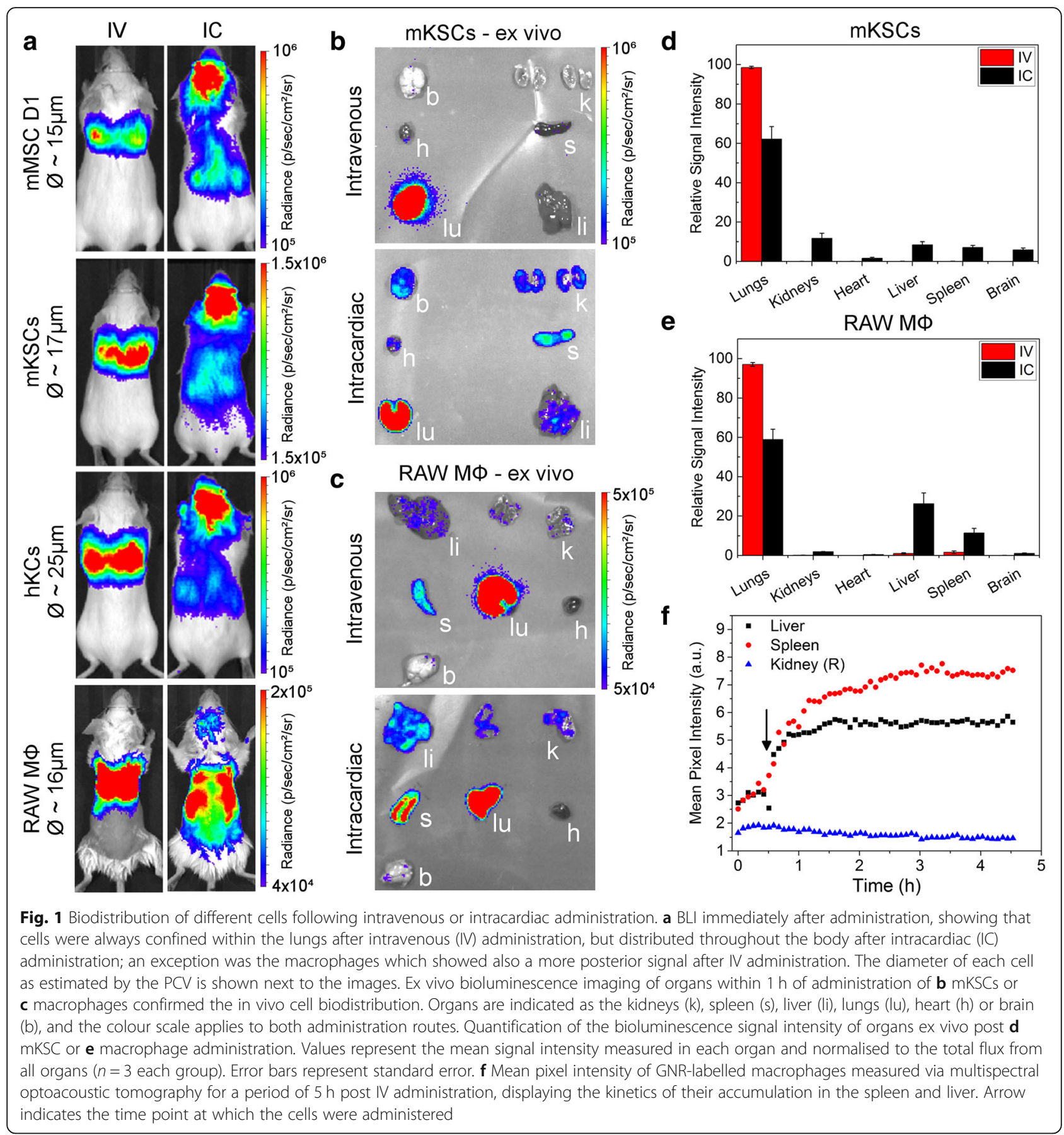

\section{Cell distribution within organs using high-resolution magnetic resonance imaging}

Since the spatial resolution of BLI is poor, we used MRI to evaluate the intra-organ biodistribution of $\mathrm{ZsGreen}^{+}$/ $\mathrm{Luc}^{+} / \mathrm{SPION}^{+}$mMSCs after IV or IC administration, focussing particularly on the brain and kidneys. Following IC injection, $\mathrm{T}_{2}$-weighted imaging revealed hypointense areas distributed homogenously throughout the brain (Fig. 2a) and localised in the cortex of the kidneys (Fig. 2b). However, the hypointense contrast was not detected in the brain or kidneys of IV-injected mice, confirming that IV administration does not deliver mMSCs to either of these organs (Fig. 2a, b). Post mortem MR imaging of extracted organs performed at higher resolution confirmed the hypointense contrast throughout the brain and in the renal cortex of IC-injected mice (Fig. 2a, b).

Histological analysis of ZsGreen expression by fluorescence microscopy in combination with Prussian blue staining of SPIONs showed that labelled cells were 


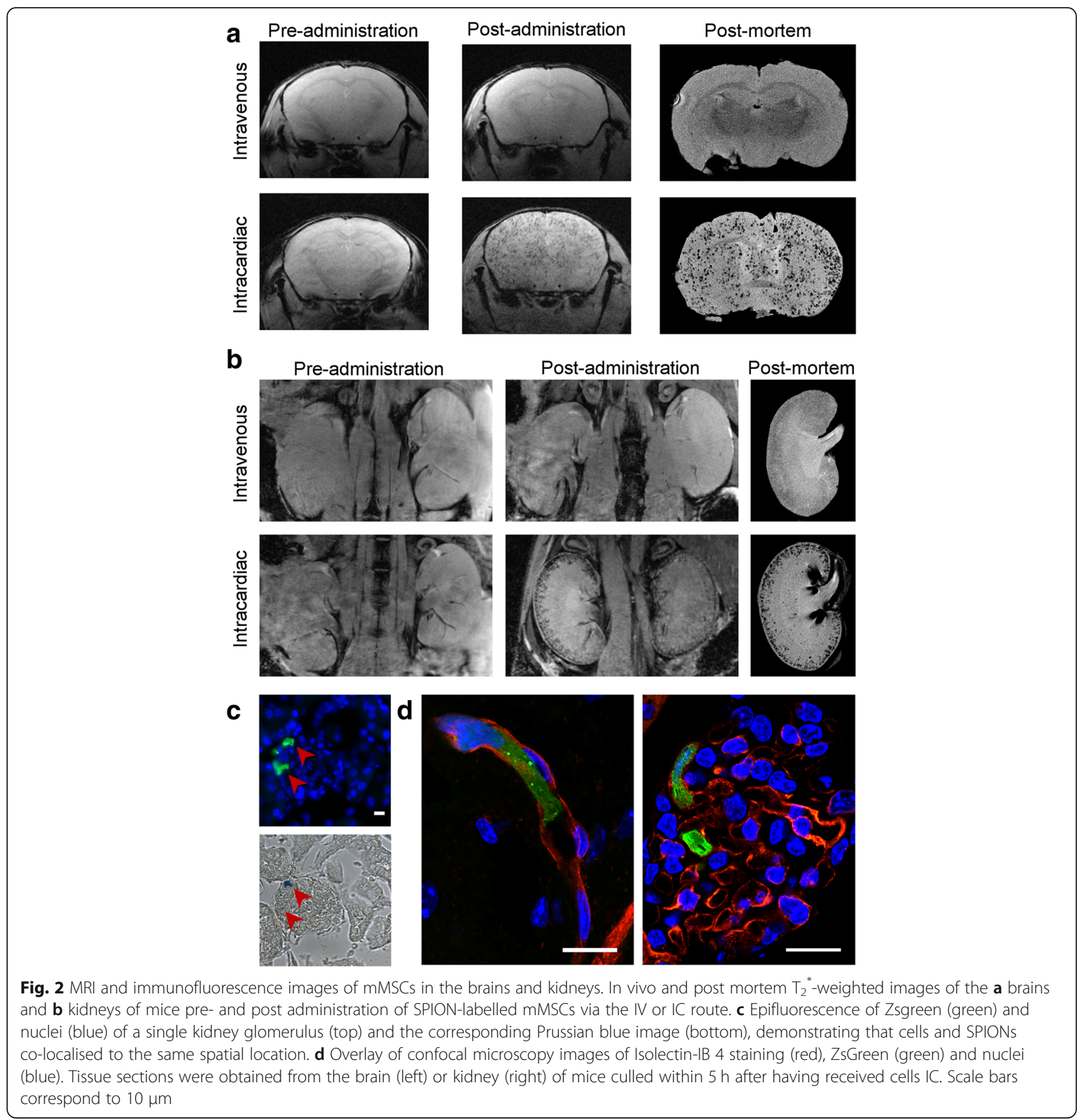

located in the renal glomeruli (Fig. 2c). ZsGreen and Prussian blue signals corresponded to the same spatial location, indicating that hypointense contrast in vivo was unlikely to result from false-positive detection of SPIONs (e.g. released from dead cells). To determine whether IC-administered cells had undergone extravasation, we performed confocal imaging of IB4-stained blood vessels in organs within $5 \mathrm{~h}$ after cell administration. This demonstrated that $Z_{s G r e e n}{ }^{+}$mMSCs were physically trapped in the lumen of microcapillaries (Fig. 2d), suggesting that the cells did not cross the blood-brain barrier or the glomerular filtration barrier.

\section{Short-term fate of IC-injected cells}

To determine how long the cells persisted in major organs, we injected $10^{6} \mathrm{ZsGreen}^{+} / \mathrm{Luc}^{+} / \mathrm{SPION}^{+}$mMSCs into the left cardiac ventricle of $\mathrm{BALB} / \mathrm{c}$ mice and tracked their fate in vivo by MRI and BLI and post mortem by MRI and fluorescence microscopy (Fig. 3a). On the day of injection (day 0), whole-body distribution of IC-administered mMSCs by bioluminescence signals was 

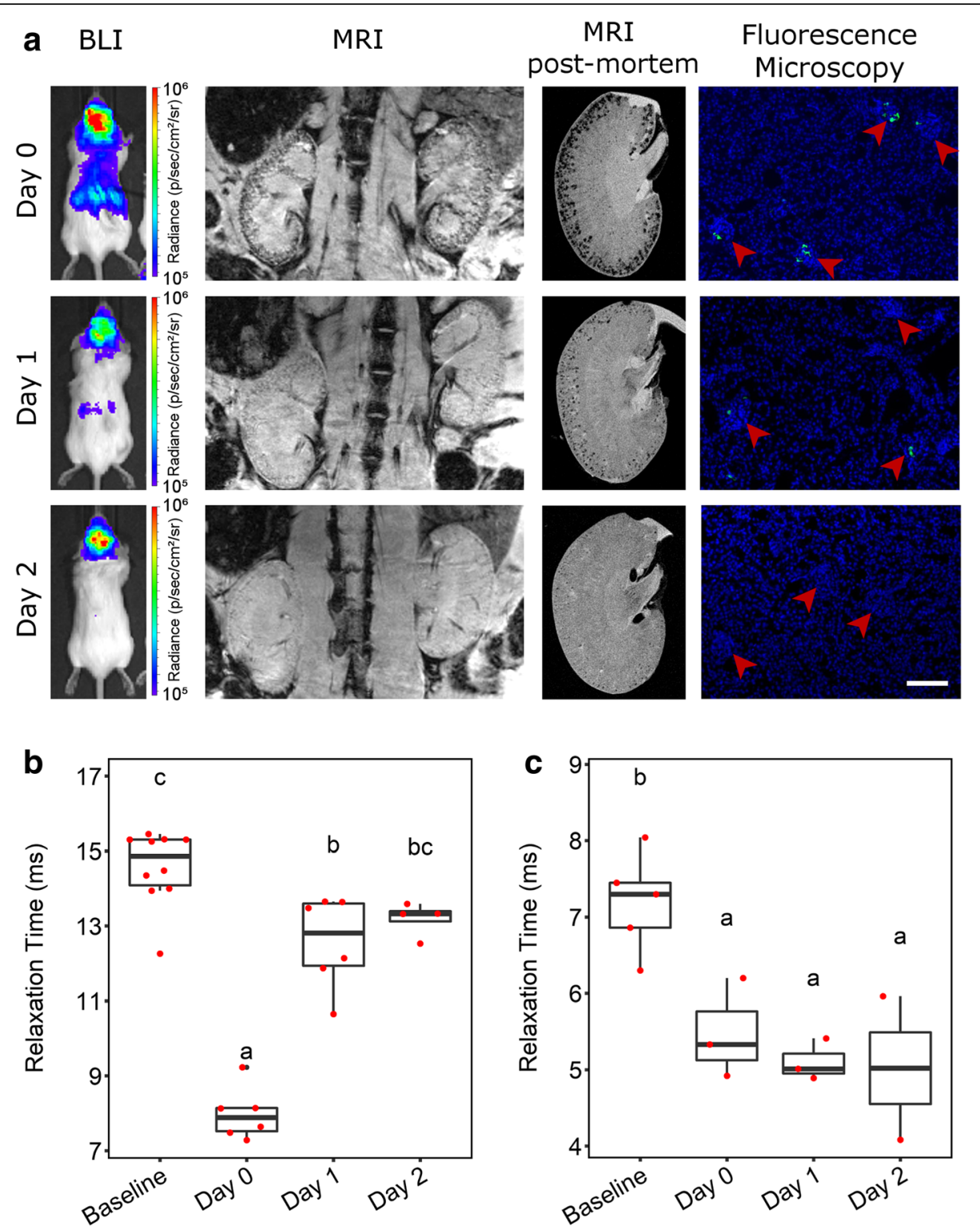

Fig. 3 Short-term fate of mMSCs imaged in vivo and post mortem. a BLI, MRI (in vivo, post mortem) and fluorescence microscopy images of the kidneys immediately (on day 0 , within 5 h) or on day 1 or day 2 after IC administration of SPION-labelled mMSCs. Fluorescence images were obtained from tissue sections where green fluorescence corresponds to ZsGreen expression and blue fluorescence to DAPI staining. Arrowheads indicate individual glomeruli. Scale bar corresponds to $100 \mu \mathrm{m}$. $\mathrm{T}_{2}^{*}$ relaxation time of the $\mathbf{b}$ kidney cortices or $\mathbf{c}$ liver before (baseline) and up to 2 days after cell administration. The $\mathrm{T}_{2}{ }^{*}$ relaxation time in the cortex of the kidney was significantly lower on the day of cell administration (day 0 , mean $=7.98 \mathrm{~ms} \pm \mathrm{SE}=0.29)$ than at baseline $(14.56 \pm 0.32 \mathrm{~ms}$; one-way ANOVA, $p<0.001)$. The $\mathrm{T}_{2}{ }^{*}$ relaxation time then increased towards baseline levels at day $1(12.57 \pm 0.50 \mathrm{~ms})$ and day $2(13.19 \pm 0.23 \mathrm{~ms})$, and by day 2 , the difference compared with baseline levels was no longer statistically significant. In the livers, $T_{2}^{*}$ relaxation time revealed a subtle but significant decrease in relaxation time from baseline to day 2 (baseline, $7.19 \pm 0.29 \mathrm{~ms}$; day 0, $5.48 \pm 0.38 \mathrm{~ms}$; day 1, $5.10 \pm 0.16 \mathrm{~ms}$; day 2, $5.02 \pm 0.94 \mathrm{~ms}$; one-way ANOVA, $p=0.006$ ). Time points that do not share the same letters are significantly different from one another, $p<0.05$ (Tukey's post hoc test)

observed, while in the kidneys, MRI revealed hypointense contrast specifically in the cortex. By day 1 , the bioluminescence signal intensity decreased, suggesting cell death. Correspondingly, fewer hypointense areas were observed in the renal cortex by MRI, supporting the disappearance of SPION-labelled cells. By day 2, bioluminescence was no longer detectable in the abdominal region, nor was any significant hypointense SPION contrast observed in the kidneys with MRI. This was confirmed by high-resolution MRI of organs ex vivo, showing a decrease in contrast in the renal cortex over time, and a decrease in the frequency of $\mathrm{ZsGreen}^{+}$ mMSCs in kidney glomeruli by fluorescence microscopy (Fig. 3a). Changes in the $\mathrm{T}_{2}{ }^{*}$ relaxation time in the renal 
cortex indicated the relative number of SPION-labelled cells present at each time point. $\mathrm{T}_{2}{ }^{*}$ was significantly lower on the day of cell administration (Fig. 3b) than at baseline but then increased towards baseline levels at day 1 and day 2. Because the liver is the major organ for clearance of blood-transported particulates, we quantified the hepatic $\mathrm{T}_{2}{ }^{*}$ relaxation time, which revealed a subtle but significant decrease from baseline through to day 2 (Fig. 3c). These results suggest that following cell death, SPIONs accumulate predominantly in the liver and are not retained by the kidneys.

\section{Effect of administration route on the long-term biodistribution and fate of mMSCs}

To assess the effect of administration route on the long-term fate of cells, $\mathrm{ZsGreen}^{+} / \mathrm{Luc}^{+}$mMSCs were administered to BALB/c SCID mice by IC or IV routes, and biodistribution was monitored by BLI at multiple time points over 30 days. While both IC and IV injection resulted in the typical immediate biodistribution patterns seen in Fig. 1a, by day 4 following IV and IC administration, the bioluminescence signal was undetectable, indicating loss of cells via cell death (Fig. 4a). Continued imaging over time showed that bioluminescence signals began to increase again in animals after IC injection from around day 14, but not in animals after IV injection. The increase in signal was particularly prominent in the hindquarters of all five IC-injected mice at day 14, and increased further until day 30 (Fig. 4a, Additional file 7a). Analysis of animals after IV administration of mMSCs revealed that in one mouse (out of three), bioluminescence signals in the lungs had increased by day 30 (Additional file 7b). Overall, whole-body bioluminescence intensity initially decreased following both IC and IV administration and subsequently increased rapidly in the IC-injected mice (Fig. 4b-d).

\section{Osteosarcoma formation after IC administration of mMSCs}

Multiple abnormal growths were present in IC-injected BALB/c SCID mice, predominantly in skeletal muscle surrounding the femurs, but also in muscle near the hips, ribs and spine (Fig. 5a, f), suggesting tumours had formed. Tumour sites corresponded to foci of intense BLI signals which could also be identified using $\mathrm{T}_{2}$-weighted MR imaging (Fig. 4e). Furthermore, $\mathrm{T}_{2}$-weighted $\mathrm{MR}$ imaging allowed us to detect an abnormal mass in the lungs of the IV-injected mouse that displayed an intense bioluminescence signal on day 30 (Fig. 4e, Additional file 7b). Although cells of the mMSC line have been suggested to home to the bone marrow [50], flow cytometry analysis showed the bone marrow was negative for $\mathrm{ZsGreen}^{+}$cells (Additional file 8). Histologically, tumours were characterised by atypical solid proliferation of spindle cells associated with multifocal formation of pale amorphous eosinophilic material (osteoid). The tumours were therefore classified as osteosarcomas (Fig. 5h, j, k). Frozen sections of the tumour tissue exhibited specific ZsGreen fluorescence (Fig. 5i), further confirming the neoplasms originated from mMSCs.

Chromosomal analysis of the mMSCs revealed a grossly abnormal karyotype of between 65 and 67 chromosomes, with multiplications and unidentified chromosomes (Additional file 9a).

\section{Formation of mMSC-derived tumours in different mouse strains}

To determine whether tumours developed because the BALB/c SCID mice were immunocompromised, we investigated the long-term fate of the mMSCs following IC administration in three different immunocompetent mouse strains: $\mathrm{BALB} / \mathrm{c}$ (same genetic background as mMSCs), FVB (unrelated inbred strain) and MF1 (unrelated outbred strain). The biodistribution immediately after injection was similar between the strains, but at day 28 , only the $\mathrm{BALB} / \mathrm{c}$ mice displayed bioluminescence signals as high as those in the BALB/c SCID mice (Fig. 5a-d). Moreover, the timing and location of tumour formation were consistent in all immunocompetent and immunocompromised $\mathrm{BALB} / \mathrm{c}$ mice. In the $\mathrm{FVB}$ and MF1 strains, mMSC foci tended to form in similar locations as with the BALB/c mice, but bioluminescence signals were weaker. Although signal intensity gradually increased in FVB mice from day 7 up to day 28, in MF1 outbred mice, signals increased initially up to day 21 , but then started to decrease as the mMSC foci began to regress (Fig. 5e).

\section{Long-term biodistribution of hUC-MSCs in BALB/C SCID mice}

Since mMSCs gave rise to tumours in immunocompromised and immunocompetent mice, predominantly after systemic arterial injection, we aimed to determine whether clinically relevant MSCs could carry a similar health risk. We focussed on well-studied hBM-MSCs as well as hUC-MSCs, as the latter are currently being used in an increasing number of clinical trials (Additional file 1). The chromosomal analysis for both hBM-MSCs and hUC-MSCs revealed a normal karyotype (Additional file 9b, c). We analysed the long-term fate of hUC-MSCs via the IC and IV route at two different cell doses, $1 \times 10^{6}$ and $5 \times 10^{5}$, showing consistent results.

When following the fate of both of these cell types after IV or IC administration in BALB/c SCID mice, we found that in most cases, BLI signals became weaker within a few days of administration and remained undetectable for the duration of the study (hBM-MSCs: 4 weeks; hUC-MSCs: 8 weeks) (Fig. 6a). Ex vivo analysis of the organs on the day of injection suggested that similar 


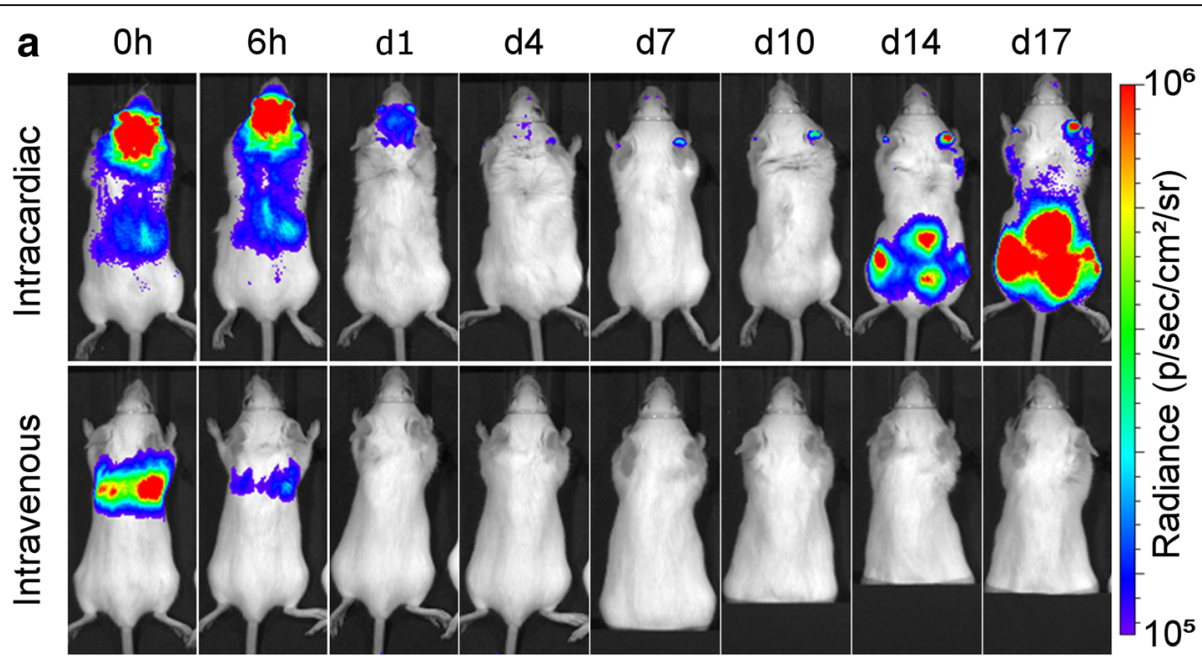

b
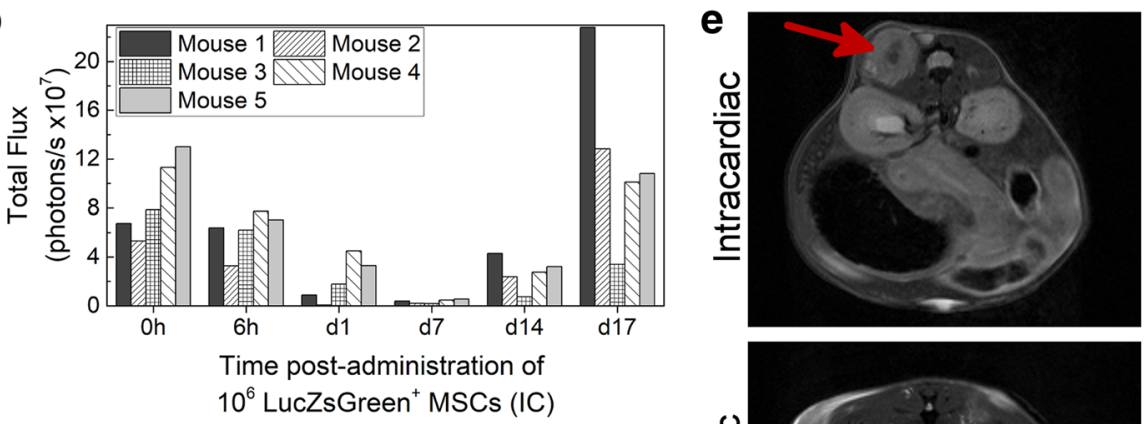

C
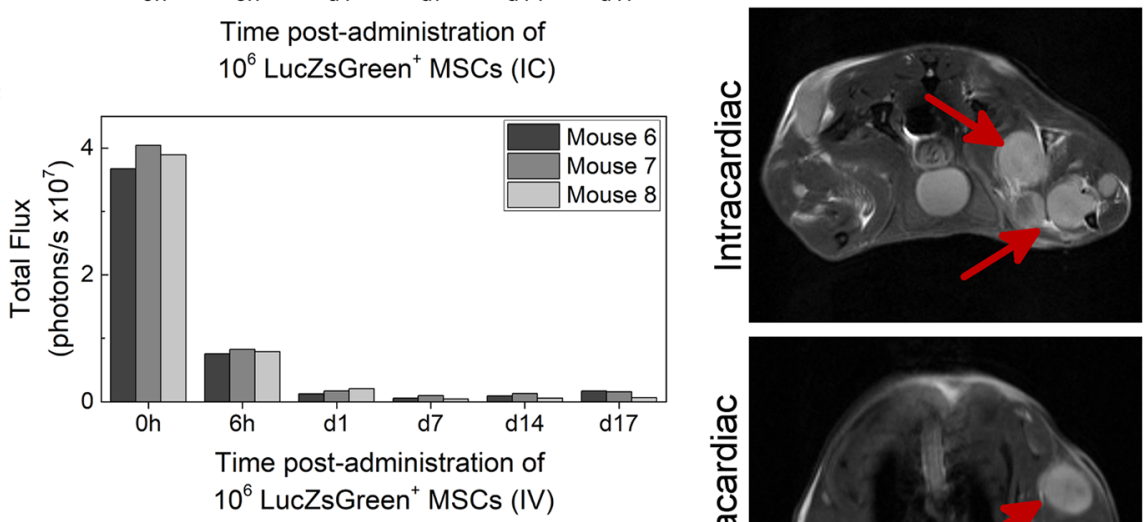

d
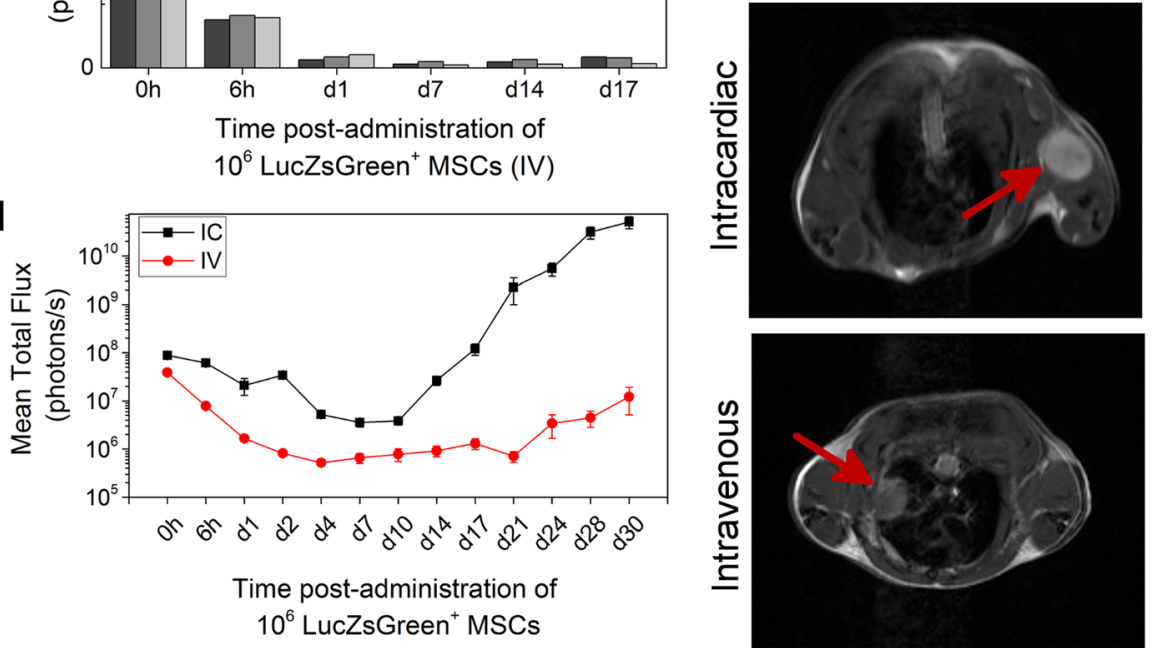

Fig. 4 Impact of administration route on long-term tumour formation. a Representative BLI of SCID mice administered with mMSC via the IC or IV route. Quantification of the bioluminescence signal from each individual mouse that received mMSCs $\mathbf{b} I C(n=5)$ or $\mathbf{c} I V(n=3)$ up to day 17. The signal corresponds to a region of interest drawn around the whole body of the mouse. $\mathbf{d}$ Mean whole-body quantification of the bioluminescence signal up to day 30. Error bars represent SE. e $T_{2}$-weighted MRI of tumours in animals that received mMSCs via IC or IV as imaged 30 days post administration. Arrows indicate individual tumours, usually in the skeletal muscle apart from the IV route, where a tumour was found close to the lungs 


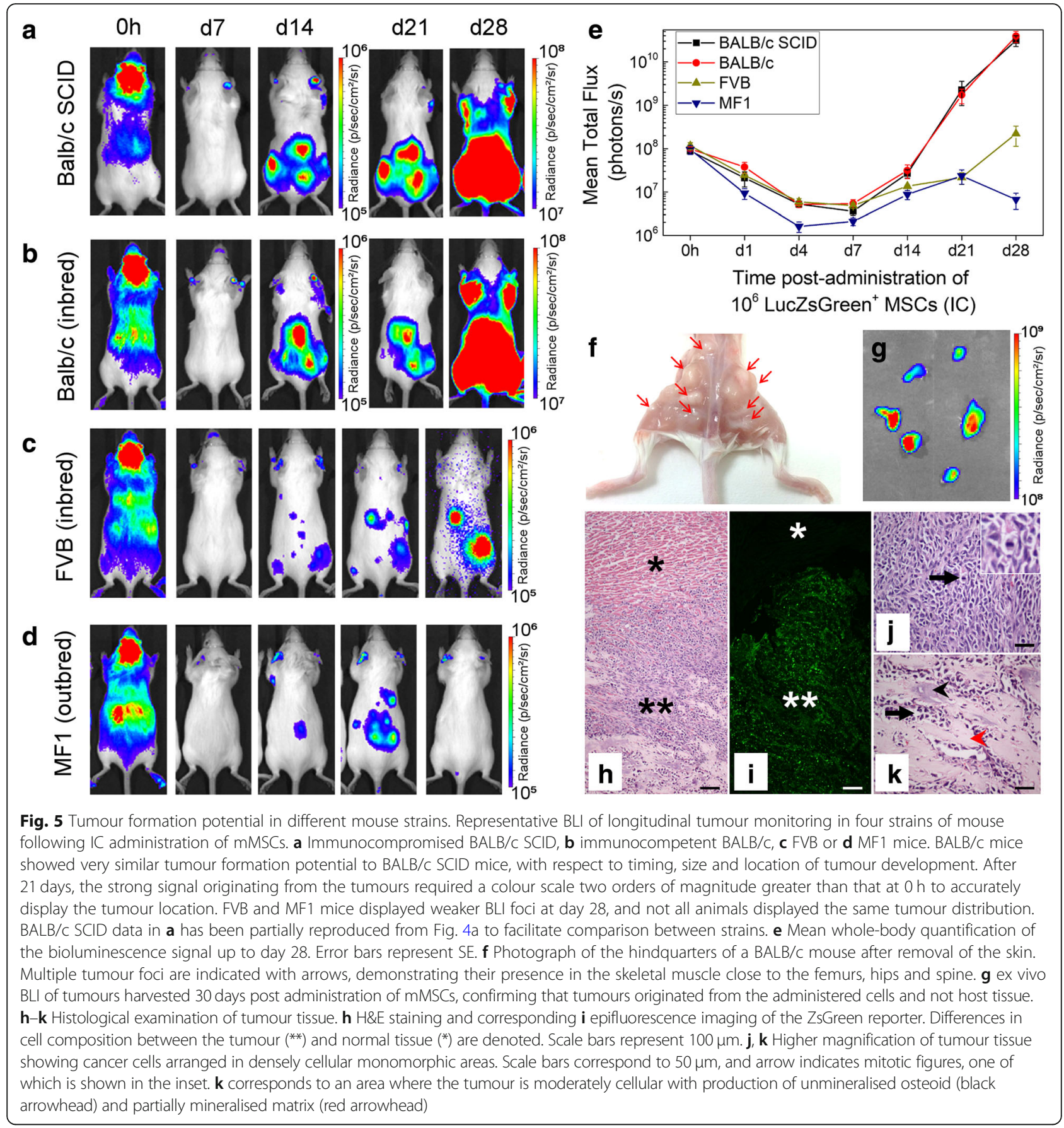

to the other cell types, a whole-body distribution was obtained when cells were injected into the arterial system, and cells were mostly trapped in the lungs when the venous route was used. However, in the case of hUC-MSCs, after IV injection the BLI signal was sometimes observed not only in the lungs but also in the heart (Fig. 6b). When imaging the same organs without the lungs, and with an increased detection sensitivity, the signal in the heart became more obvious, while very weak signals could also be observed in other organs (Additional file 10). Interestingly, long-term imaging of mice that had received hUC-MSCs via the IV route revealed that in a small number of animals $(\sim 25 \%)$ foci had developed in locations beyond the lungs (Fig. 6c, red arrows), although in all cases these regressed within the time course of the experiment.

\section{Discussion}

Here, we have employed a novel platform approach of non-invasive preclinical imaging encompassing BLI, MRI and MSOT to assess the biodistribution and persistence 


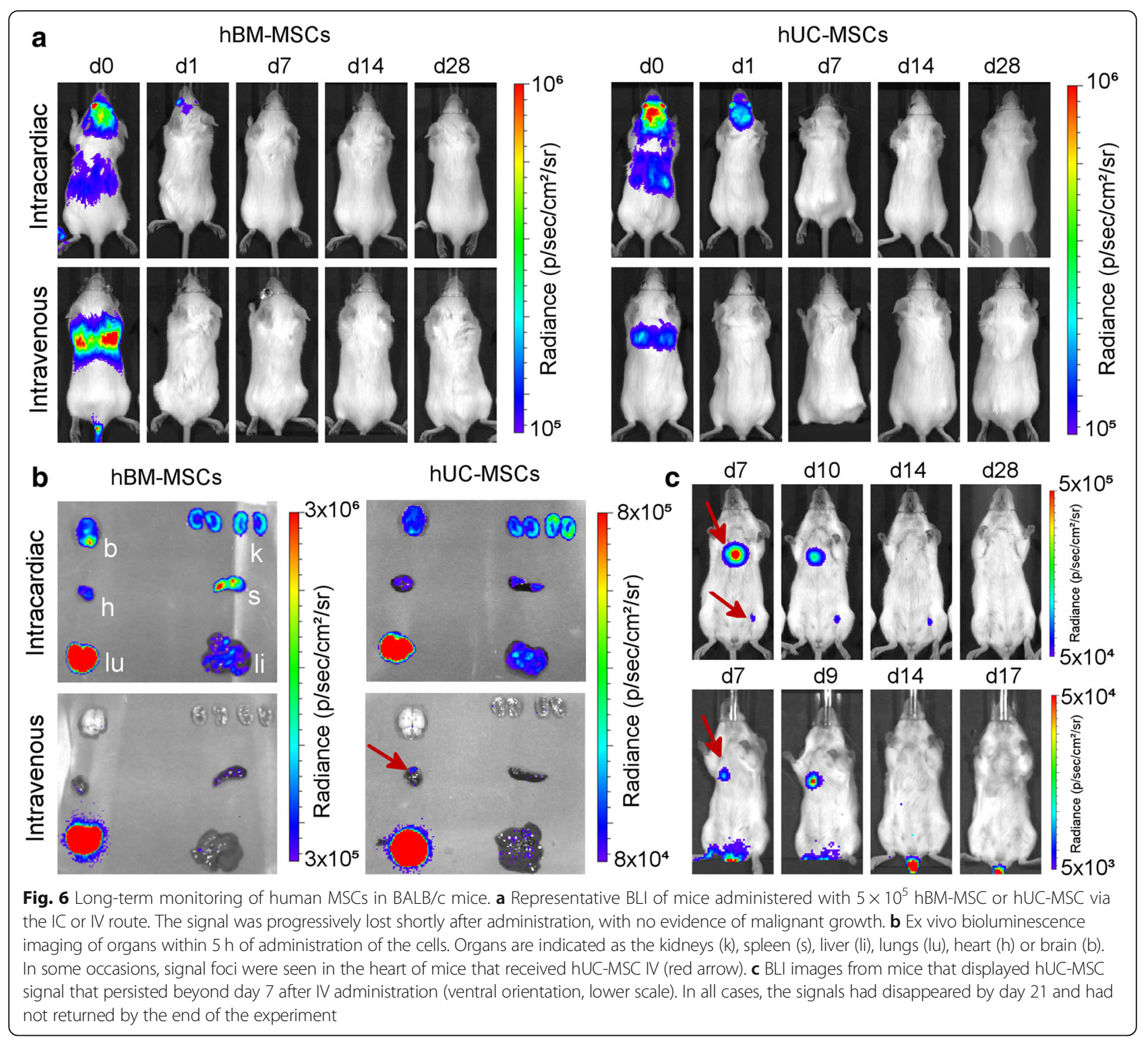

of a range of mouse and human cell types following IV and IC administration in healthy mice. These cells included mouse MSCs, kidney stem cells and macrophages, as well as human kidney-derived cells and two types of human MSCs, which are already being tested as cell therapies in clinical trials.

As expected, immediate analysis after IV administration revealed that apart from macrophages, all other cell types were mostly sequestered in the lungs, although small numbers of hUC-MSCs could be detected in other organs following ex vivo analysis. After IC administration, all cell types showed a widespread distribution. However, irrespective of the administration route, analysis using BLI and MRI determined that cells disappeared from major organs within $24-48 \mathrm{~h}$, which based on the loss of BLI signals, was likely due to cell death.
A number of preclinical cell therapy studies have reported that IV-administered cells reached the relevant injured organs, where they incorporated and contributed to the regeneration of healthy and functional tissue $[7,9,10$, $51,52]$. It had been postulated that the mechanisms by which the cells, especially MSCs, reached the injured organs was based on the release of trophic factors which attracted the cells to the relevant injury site [33, 53]. An important problem with these studies was that cells had mostly been labelled with membrane dyes (DiI or PKH26) which were detected in the injured organ. However, as we have recently demonstrated, membrane dyes easily dissociate from the cells, leading to misinterpretation of the presence of administered cells [32]. Therefore, more sophisticated approaches to cell labelling and tracking have been established, including bioluminescence imaging of 
luciferase-transduced cells $[17,54]$. This method is specific to living cells because the signal is dependent on production of the enzyme luciferase. Here, we have demonstrated, as others before $[32,34,55,56]$, that IV-administered cells are generally sequestered in the first vascular bed they encounter, which is the lung microvasculature, where they die and then disappear within 2 days.

Since a number of preclinical studies have shown that administered cells fail to incorporate and directly contribute to the regeneration of the damaged tissue in injured organs despite leading to beneficial effects in organ function and histology, it is highly relevant to understand the mechanisms by which efficacy is provided. Increasing evidence points towards paracrine factors that are released by the dying cells. This probably occurs through activation of immunomodulatory pathways that initiate regeneration or, possibly, also via other protective functions [31, 32, 56]. It is currently not understood whether these effects are based on direct and short-term interactions between cytokines and immune cells, stimulating an anti-inflammatory switch, or if epigenetic changes are involved, which could lead to long-term effects.

We explored an alternative systemic administration route by injecting cells directly into the left ventricle of the heart and demonstrated that this route delivered the cells directly to organs, instead of sequestration in the lungs. Our observation that cells are cleared very quickly from the major organs following IC administration indicates that the arterial route poses no significant advantage for cell therapy administration. However, it is possible that small numbers of cells reaching the organs after IC administration may still be able to locally exert beneficial roles through paracrine effects before they are cleared. Therefore, further research is required to explore the local role of IC-delivered cells.

Using our platform of imaging techniques, we were able to provide some mechanistic insight into the fate of macrophages after administration, which have been demonstrated to confer beneficial effects in organ injury models $[57,58]$. Macrophages have been previously shown to home to the liver and spleen after passage through the lungs [59]. However, the dynamics of this homing process had not been described. Using multi-modal BLI and MSOT [24], we could monitor macrophage accumulation in the liver and spleen for $4.5 \mathrm{~h}$ continuously at high temporal resolution. We found that labelled macrophages immediately started to accumulate in the liver and spleen, particularly in the first $\sim 90 \mathrm{~min}$, which indicated that some of the macrophages instantly passed through the pulmonary circulation.

While BLI has the advantage of highly sensitive body-wide detection of luciferase-expressing cells, its spatial resolution is poor, which prevents organ-focussed imaging. To visualise cells within major organs such as the kidney and brain and monitor their fate over time, we implemented a bimodal approach comprising BLI and MRI, taking advantage of the high spatial resolution of MRI in addition to the high sensitivity of BLI and the fact that luciferase activity is dependent on cell viability [15-18].

It should be noted that labelling of cells for preclinical imaging approaches raises a number of questions regarding the interpretation of the findings. While lentiviral labelling is typically a process that results in stable expression of the reporter protein of interest, and as in our case of luciferase, with high sensitivity, exposure to lentiviral particles and the resulting expression of exogenous proteins could possibly affect the immunogenicity of the cells [60], which may have downstream effects on recognition by the endogenous immune system. Because we have used SCID mice for most of our studies, especially those with human MSCs, possible immunogenicity will unlikely have affected the results. In addition, luciferase signal will disappear when cells are phagocytosed, but may remain if cells undergo cell fusion. Therefore, loss of BLI signal is a clear sign of loss of cells through cell death, while continued presence of signal could also indicate a change in cell phenotype by cell fusion. By contrast, SPION or GNR labels may still be detectable after cells have been phagocytosed or fused, potentially leading to misinterpretation. To our knowledge, SPIONs and GNRs have not shown to modify the immunogenicity of labelled cells. To avoid false signals, dual or triple labelling of cells using a combination of genetic direct reporters and nanoparticles could address this problem. We have recently shown that a combination of labels can indeed provide detailed information on the dynamics of cell fate, as GNR-labelled mouse MSCs which also expressed a near-infrared reporter protein disappeared within 2 days after IC injection from the various organs in which they could be detected initially, and instead GNRs accumulated in the liver. By contrast, the reporter protein visualised the increase in cells in tumours forming in sites similar to the ones reported here [24]. A genetic reporter is highly suitable for the detection of multiplying cells, for example in tumours, where the GNRs or other nanoparticles would get diluted out with increasing numbers of cell divisions.

Our detailed analysis of the biodistribution of mMSCs after IC injection using in vivo and subsequently ex vivo MR imaging techniques revealed that SPION-labelled cells were scattered throughout the brain, while in the kidneys, they were restricted to the cortical regions. Ex vivo histological staining and fluorescence microscopy demonstrated that cells in the kidneys were found only within the glomeruli, bounded by endothelial cells within 
the microvasculature, where they appeared to be trapped. Similarly, cells in the brain were only localised within the microvasculature, indicating that they lack the capacity to pass through the blood-brain barrier. These results demonstrate that the mMSCs cannot extravasate into the brain and kidneys.

During long-term cell tracking of the BALB/c-derived mMSCs, we observed tumour formation in skeletal muscle following IC administration to a similar degree in immunocompetent $\mathrm{BALB} / \mathrm{c}$ mice as in BALB/c SCIDs. mMSCs also gave rise to tumours in an unrelated inbred strain, albeit at a slower rate, while in an unrelated outbred strain, small foci of mMSCs expanded at early time points and later regressed. Taken together, these data suggest that the adaptive immune system might not be able to recognise tumours derived from syngeneic MSCs and that the genetic background of the host appears to have an effect on the propensity of MSCs to form tumours. This could be a concern for human trials using autologous MSCs where the ability of the cells to form tumours may not be detected by the recipient's immune system. Furthermore, the results suggest that the risk of tumour formation might depend on undefined genetic factors that would vary from patient to patient. However, it is important to note that karyotype testing of the mMSC line used here revealed a range of chromosomal abnormalities, which could contribute to their propensity to form tumours. In a recent study, a clonal mouse MSC line derived from the immortomouse was found to persist for up to 33 weeks after intra-arterial injection, in the distal femur of SCID mice in which the respective leg had been injured by irradiation [55]. However, while the BLI signal of firefly luciferase expressed by the mMSCs increased over time, tumours were not reported.

Our observation that mMSCs distributed to most organs following IC injection, but tumours were predominantly localised in the skeletal muscles and not within the organs they originally appeared in, raises the question of how tumour formation is regulated in different organs and tissues. Our data indicate that the cells had a 'survival advantage' in muscular tissue, but not in the brain and the kidneys, from which they failed to extravasate. We hypothesise that following IC administration, a small number of MSCs were able to extravasate from the capillaries in the skeletal muscle where they started to proliferate. The mechanisms that regulate the ability of the mMSCs to extravasate and form tumours in the skeletal muscle but not in other organs are not known, and further analysis is required to determine the molecular and cellular factors controlling this process.

Our results also show that the cells failed to home to and populate the bone marrow, which is surprising given the cells had been originally isolated from this tissue
[61]. The D1 mMSC line used here has not previously been reported to generate invasive tumours, since subcutaneously injected cells provided no evidence of metastasising, even if they proliferated at the injection site [23, 62]. Our observation that the mMSCs did not form tumours outside the lung following IV administration is therefore consistent with this finding. However, the formation of osteosarcomas in the skeletal muscle after IC administration of mMSCs in this study is in line with the previously described formation of osteosarcomas after adoptive transfer of primary MSCs, particularly for cells expanded in vitro, and is a major safety concern in therapies using MSCs [63, 64].

Since these observations suggested that arterial administration of MSC-based cell therapies could have important safety implications, we followed the fate of MSC derived from the bone marrow or the umbilical cord of healthy human donors. We confirmed that neither of these cells presented any major chromosomal aberrations, even after transduction with the luciferase reporter. While in most animals the cells became undetectable within a few days after IV administration, in a few mice, the hUC-MSCs persisted longer, albeit transiently, in other body regions where their presence was not expected. Of note, a transient persistence of hUC-MSCs was not observed after IC administration, nor for hBM-MSCs using IV or IC administration routes. We suggest that this unusual behaviour is not linked to cell size, because the hUC-MSCs are not smaller than mKSCs or mMSCs, but could possibly be due to their surface proteins, allowing some of the cells to escape the lungs $[33,65]$. The observation that hUC-MSC foci appeared in a small number of mice, grew in size, but later disappeared, was difficult to explain, especially given that the mice were SCIDs and thus lacked an adaptive immune system. It is possible that the cells eventually elicited a xenogeneic response involving macrophages and natural killer cells [66], after initially suppressing the native immune system, which is one of their central properties [67,68]. Alternatively, the hUC-MSCs may have expanded in the animal but then become senescent and died, irrespective of the host's ability to mount an immune response. Thus, after an 8-week period of cell tracking, we could not observe any tumour growth by in vivo or ex vivo BLI in all SCID mice to which hUC-MSCs had been administered by either IV or IC injection. However, the observation that the IV-injected hUC-MSCs persisted for a time period in $25 \%$ of the animals indicates that these cells carry greater safety risks and suggests that clinical therapies with these cells should proceed with caution with an appropriate risk management plan. Further preclinical studies are needed to determine the mechanisms by which hUC-MSCs were able to persist as well as 
eventually disappear in order to better define the potential for tumourigenicity. The imaging platform presented here provides the necessary biotechnology for preclinical evaluation of the potential tumourigenicity of cell products used for cell transplantation, for which there is presently no internationally recognised guideline.

\section{Conclusions}

Cell-based therapies are currently being considered for a range of diseases, some of which are already undergoing clinical trials. A robust biodistribution and safety assessment is essential for understanding cell fate and ensuring patient welfare. Here, we demonstrate a safety assessment platform that can expose not only the general organ distribution of potential cell therapies, but also a detailed view of their presence within different organs. Importantly, by using this imaging platform, we show that the route of administration affects the range of organs that the cells can reach and, particularly, their propensity to form tumours. Our assessment suggests that cells are short-lived irrespective of whether they are administered via the venous or arterial circulation and that the risk of cell persistence or tumour formation is dependent on the cell type, route of administration and immune status of the host. Crucially, we show that clinically used, human umbilical cord-derived mesenchymal stem/stromal cells form transient unexpected self-limited proliferations in various anatomical regions when administrated intravenously. The implications of this observation require further investigations and should be taken into account when clinical trials are considered.

\section{Additional files}

Additional file 1: Summary of registered clinical studies involving umbilical cord-derived MSCs. (PDF $374 \mathrm{~kb}$ )

Additional file 2: Culture media used for growing cells. (PDF $326 \mathrm{~kb}$ ) Additional file 3: Detailed method of ultrasound-guided intracardiac injection of cells. (PDF $772 \mathrm{~kb}$ )

Additional file 4: MSOT images of GNR-labelled macrophages in different organs. Snapshot images of the abdomen of mice, showing the (a) liver, delineated with red lines and (b) kidney, delineated with a yellow line or spleen, delineated with a green line. Images correspond to baseline imaging (pre-administration) and $4 \mathrm{~h}$ post IV administration of GNR-labelled RAW macrophages. GNR-labelling generates MSOT contrast, seen as an increase in pixel brightness for areas corresponding to liver and spleen. Kinetic imaging over a period of $4 \mathrm{~h}$ was used to generate data shown in Fig. 1f. (c) Quantification of the MSOT mean pixel intensity in the liver, spleen or kidneys $4 \mathrm{~h}$ post administration of GNR-labelled RAW macrophages IV or IC. Data is displayed as fold changes in pixel intensity in respect to baseline measurements. (PDF $463 \mathrm{~kb}$ )

Additional file 5: Placement of a region of interest (ROI) for the calculation of relaxation time in the kidney's cortex. (a) In vivo $T_{2}{ }^{*}$-weighted image of a single kidney post administration of SPION-labelled mMSCs, (b) placement of an ROI (yellow line) covering the cortex of the kidney where cell/SPION contrast is observed and (c) the changes in signal intensity as a function of echo time, with the solid line displaying the exponential fit of the data, from where the relaxation time is derived. Relaxation times were calculated with Paravision 6.0.1. (PDF $462 \mathrm{~kb}$ )

Additional file 6: MRI sequences and acquisition parameters. All in vivo data was acquired with a 4-channel surface coil designed for the mouse brain or abdomen. Post mortem data was obtained with a $27 \mathrm{~mm}$ volume coil. (PDF 547 kb)

Additional file 7: mMSC distribution between day 14 and 30. (a) From day 24 onwards for IC-injected mice, it was necessary to increase the scale by two orders of magnitude (BLI scale $1.0 \times 10^{7}-1.0 \times 10^{8} \mathrm{p} / \mathrm{s} / \mathrm{cm} 2$ / $\mathrm{sr}$, orange frame) compared to that in Fig. 4 to enable visualisation of the very strong signals resulting from rapidly proliferating mMSCs. (b) Using the original scale (see Fig. 4: $1.0 \times 10^{5}-1.0 \times 10^{6} \mathrm{p} / \mathrm{s} / \mathrm{cm} 2 / \mathrm{sr}$ ), signals could be detected by day 24 in one (out of 3) IV-injected mice. (c, e) Representative in vivo and corresponding (d, f) ex vivo organ images at day 30. (d) Small spots of bioluminescence signal could be detected in some of the organs of IC-injected BALB/C SCID mice (arrows), but the scale had to be lowered to $1.0 \times 10^{4}-1.0 \times 10^{5} \mathrm{p} / \mathrm{s} / \mathrm{cm} 2 / \mathrm{sr}$ (blue frame) in order to be able to display these weak signals. (e) Two out of three IV-administered BALB/ c SCID mice did not show any signals at day 30 in vivo using the standard scale (green frame), however, corresponding ( $f$ ) organ imaging showed small foci of bioluminescence signals in the lungs (arrows). (PDF $618 \mathrm{~kb}$ )

Additional file 8: Fluorescence Activated Cell Sorting (FACS) analysis of bone marrow extracts. Green fluorescence analysis of cells harvested from the femurs and tibias of (a) a control mouse that received no cells (b) a mouse that received mMSCs IC display no evidence of ZsGreen+ cells in the bone marrow. (PDF $351 \mathrm{~kb}$ )

Additional file 9: Chromosome analysis of the (a) mMSCs, (b) hBM-MSCs and (c) hUC-MSCs. Whereas mMSCs displayed a grossly abnormal karyotype, the human cells displayed a normal female karyotype. (PDF $422 \mathrm{~kb}$ )

Additional file 10: Ex vivo imaging of organs immediately after administration of $10^{6}$ hUC-MSC. (a) Intracardiac administration always results in BLI signal originating from organs in addition to the lungs. Intravenous administration, on the other hand, leads to cells lodging predominantly in the lungs. For hUC-MSCs, however, a weak signal was seen in heart, which was particularly noticeable when the lungs were removed from the imaging field. BLI scale: all organs $1.0 \times 10^{5}-1.0 \times 10^{7} \mathrm{p} / \mathrm{s} / \mathrm{cm} 2 / \mathrm{sr}$, lungs removed: $1.0 \times 10^{4}-4.0 \times 10^{5} \mathrm{p} / \mathrm{s} / \mathrm{cm} 2 / \mathrm{sr}$. (b, c) Relative bioluminescence intensity in each organ as measured ex vivo post (b) IC or (c) IV administration. The signal intensity of mKSCs as shown in Fig. 1d is displayed as a reference. Note that following IV administration, the sum of the signal in organs other than the lungs is generally less than $2 \%$ of the total. A break has been inserted in the $y$-axis to facilitate the visualisation of the data. (PDF $486 \mathrm{~kb}$ )

\section{Abbreviations}

ANOVA: Analysis of variance; BLI: Bioluminescence imaging; FACS: Fluorescenceactivated cell sorting; GNRs: Gold nanorods; H\&E: Haematoxylin and eosin; hBMMSCs: Human bone marrow-derived mesenchymal stem/stromal cells; hKCs: Human kidney cells; hUC-MSCs: Human umbilical cord-derived mesenchymal stem/stromal cells; IC: Intracardiac; IV: Intravenous; luc: Luciferase (from firefly); mKSCs: Mouse kidney-derived stem cells; mMSCs: Mouse mesenchymal stem/stromal cells (D1 line); MOI: Multiplicity of infection; MRI: Magnetic resonance imaging; MSCs: Mesenchymal stem/stromal cells; MSOT: Multispectral optoacoustic tomography; PBS: Phosphate-buffered saline; PCV: Packed cell volume; RMTs: Regenerative medicine therapies; ROI: Region of interest; SCID: Severe combined immunodeficient; SPIONs: Superparamagnetic iron oxide nanoparticles

\section{Acknowledgements}

The authors would like to thank Carmel Moran and Adrian Thomson, University of Edinburgh, Tammy Kalber and Daniel Stuckey, University College London, and Aleksandra Rak-Raszewska, for providing help and technical guidance in optimising the US-IC injection method, and Thomas Wilm, University of Liverpool, for helping with the confocal imaging. All in vivo imaging was carried out in the Centre for Preclinical Imaging, University of Liverpool.

\section{Funding}

We gratefully acknowledge support by the MRC, EPSRC and BBSRC-funded UK Regenerative Medicine Platform 'Safety and Efficacy, focussing on 
Imaging Technologies Hub' (MR/K026739/1); by a Marie Curie Fellowship to Joan Comenge (NANOSTEMCELLTRACKING); and by the FP7 Marie Curie Initial Training Network 'NephroTools' and Alder Hey Children's Kidney Fund. The funding bodies had no role in the design of the study and collection, analysis, and interpretation of data, nor in the writing of the manuscript. Cai Astley and Lydia Beeken were self-funded in this project.

\section{Availability of data and materials}

The datasets supporting the conclusions of this article are included within the article and its additional files.

\section{Authors' contributions}

LS, AT, JSh, RH, LB and CA contributed to the conception and design, acquisition and/or assembly of data, data analysis and interpretation, manuscript writing and final approval of the manuscript. MB, JC, IS and LR contributed to the acquisition and/or assembly of data and final approval of the manuscript. JSm and EA contributed to the provision of study material and final approval of manuscript. $\mathrm{CH}, \mathrm{RL}, \mathrm{MJR}$, DJA, HP and BKP contributed to the conception and design, data analysis and interpretation and final approval of manuscript. PM and BW contributed to the conception and design, data analysis and interpretation, manuscript writing and final approval of manuscript.

\section{Ethics approval and consent to participate}

All animal experiments were performed under a licence granted under the revised UK Animals (Scientific Procedures) Act 1986 and were approved by the University of Liverpool ethics committee.

\section{Consent for publication}

\section{Not applicable}

\section{Competing interests}

The authors declare that they have no competing interests.

\section{Publisher's Note}

Springer Nature remains neutral with regard to jurisdictional claims in published maps and institutional affiliations.

\section{Author details}

${ }^{1}$ Department of Cellular and Molecular Physiology, University of Liverpool, Liverpool, UK. ${ }^{2}$ Centre for Preclinical Imaging, University of Liverpool, Liverpool, UK. ${ }^{3}$ Department of Molecular and Clinical Pharmacology, Institute of Translational Medicine, University of Liverpool, Liverpool, UK. ${ }^{4}$ Department of Chemistry, University of Liverpool, Liverpool, UK. ${ }^{5}$ Institute of Integrative Biology, University of Liverpool, Liverpool, UK. ${ }^{6}$ Department of Veterinary Pathology and Public Health, Institute of Veterinary Science, University of Liverpool, Liverpool, UK. ${ }^{7} \mathrm{NHS}$ Blood and Transplant, Oxford, UK. ${ }^{8}$ School of Chemistry, College of Science and Engineering, University of Glasgow, Glasgow, UK. ${ }^{9}$ Department of Cellular and Molecular Physiology, Institute of Translational Medicine, University of Liverpool, Liverpool L69 3BX, UK.

Received: 22 June 2018 Revised: 23 October 2018 Accepted: 12 November 2018 Published online: 28 November 2018

\section{References}

1. Buzhor E, Leshansky L, Blumenthal J, Barash H, Warshawsky D, Mazor Y, Shtrichman R. Cell-based therapy approaches: the hope for incurable diseases. Regen Med. 2014;9:649-72.

2. Heslop JA, Hammond TG, Santeramo I, Tort Piella A, Hopp I, Zhou J, Baty R, Graziano El, Proto Marco B, Caron A, et al. Concise review: workshop review: understanding and assessing the risks of stem cell-based therapies. Stem Cells Transl Med. 2015;4:389-400.

3. Lalu MM, McIntyre L, Pugliese C, Fergusson D, Winston BW, Marshall JC, Granton J, Stewart DJ. Safety of cell therapy with mesenchymal stromal cells (SafeCell): a systematic review and meta-analysis of clinical trials. PLoS One. 2012;7:e47559.

4. Toyserkani N, Gustaf Jørgensen M, Tabatabaeifar S, Jensen C, Sheikh S, Sørensen J. Concise review: a safety assessment of adipose-derived cell therapy in clinical trials: a systematic review of reported adverse events: safety of adipose-derived cell therapy. Stem Cells Transl Med. 2017;6: 1786-94.
5. Li X, Bai J, Ji X, Li R, Xuan Y, Wang Y. Comprehensive characterization of four different populations of human mesenchymal stem cells as regards their immune properties, proliferation and differentiation. Int J Mol Med. 2014;34:695-704.

6. Berkowitz AL, Miller MB, Mir SA, Cagney D, Chavakula V, Guleria I, Aizer A, Ligon $\mathrm{KL}$, Chi JH. Glioproliferative lesion of the spinal cord as a complication of "stem-cell tourism". N Engl J Med. 2016;375:196-8.

7. Jang HR, Park JH, Kwon GY, Lee JE, Huh W, Jin HJ, Choi SJ, Oh W, Oh HY, Kim YG. Effect of preemptive treatment with human umbilical cord blood derived mesenchymal stem cells on the development of renal ischemiareperfusion injury in mice. Am J Physiol Renal Physiol. 2014;307: F1149-61.

8. Chen YT, Sun CK, Lin YC, Chang LT, Chen YL, Tsai TH, Chung SY, Chua S, Kao YH, Yen $\mathrm{CH}$, et al. Adipose-derived mesenchymal stem cell protects kidneys against ischemia-reperfusion injury through suppressing oxidative stress and inflammatory reaction. J Transl Med. 2011;9:51.

9. Ronconi E, Sagrinati C, Angelotti ML, Lazzeri E, Mazzinghi B, Ballerini L, Parente E, Becherucci F, Gacci M, Carini M, et al. Regeneration of glomerular podocytes by human renal progenitors. J Am Soc Nephrol. 2009;20:322-32.

10. Angelotti ML, Ronconi E, Ballerini L, Peired A, Mazzinghi B, Sagrinati C, Parente $\mathrm{E}$, Gacci M, Carini M, Rotondi M, et al. Characterization of renal progenitors committed toward tubular lineage and their regenerative potential in renal tubular injury. Stem Cells. 2012;30:1714-25.

11. Morigi M, Introna M, Imberti B, Corna D, Abbate M, Rota C, Rottoli D, Benigni A, Perico N, Zoja C, et al. Human bone marrow mesenchymal stem cells accelerate recovery of acute renal injury and prolong survival in mice. Stem Cells. 2008;26:2075-82.

12. Li P, Zhang R, Sun H, Chen L, Liu F, Yao C, Du M, Jiang X. PKH26 can transfer to host cells in vitro and vivo. Stem Cells Dev. 2013;22:340-4.

13. Taylor A, Wilson KM, Murray P, Fernig DG, Levy R. Long-term tracking of cells using inorganic nanoparticles as contrast agents: are we there yet? Chem Soc Rev. 2012;41:2707-17.

14. Kircher MF, Gambhir SS, Grimm J. Noninvasive cell-tracking methods. Nat Rev Clin Oncol. 2011;8:677-88.

15. Paley MA, Prescher JA. Bioluminescence: a versatile technique for imaging cellular and molecular features. MedChemComm. 2014;5:255-67.

16. Lyons SK, Patrick PS, Brindle KM. Imaging mouse cancer models in vivo using reporter transgenes. Cold Spring Harb Protoc. 2013;2013:685-99.

17. Scarfe L, Brillant N, Kumar JD, Ali N, Alrumayh A, Amali M, Barbellion S, Jones $\mathrm{V}$, Niemeijer $\mathrm{M}$, Potdevin $\mathrm{S}$, et al. Preclinical imaging methods for assessing the safety and efficacy of regenerative medicine therapies. npj Regen Med. 2017;2:28.

18. Kim JE, Kalimuthu S, Ahn B-C. In vivo cell tracking with bioluminescence imaging. Nucl Med Mol Imaging. 2015;49:3-10.

19. Togel F, Yang Y, Zhang P, Hu Z, Westenfelder C. Bioluminescence imaging to monitor the in vivo distribution of administered mesenchymal stem cells in acute kidney injury. Am J Physiol Renal Physiol. 2008;295:F315-21.

20. Wise AF, Williams TM, Kiewiet MB, Payne NL, Siatskas C, Samuel CS, Ricardo SD. Human mesenchymal stem cells alter macrophage phenotype and promote regeneration via homing to the kidney following ischemiareperfusion injury. Am J Physiol Renal Physiol. 2014;306:F1222-35.

21. Ricles LM, Nam SY, Trevino EA, Emelianov SY, Suggs LJ. A dual gold nanoparticle system for mesenchymal stem cell tracking. J Mater Chem B Mater Biol Med. 2014;2:8220-30.

22. Jokerst JV, Thangaraj M, Kempen PJ, Sinclair R, Gambhir SS. Photoacoustic imaging of mesenchymal stem cells in living mice via silica-coated gold nanorods. ACS Nano. 2012;6:5920-30.

23. Comenge J, Fragueiro O, Sharkey J, Taylor A, Held M, Burton NC, Park BK, Wilm B, Murray P, Brust M, Levy R. Preventing plasmon coupling between gold nanorods improves the sensitivity of photoacoustic detection of labeled stem cells in vivo. ACS Nano. 2016;10:7106-16.

24. Comenge J, Sharkey J, Fragueiro O, Wilm B, Brust M, Murray P, Levy R, Plagge A. Multimodal cell tracking from systemic administration to tumour growth by combining gold nanorods and reporter genes. eLife. 2018;7: e33140.

25. Barrow M, Taylor A, García Carrión J, Mandal P, Park BK, Poptani H, Murray P, Rosseinsky MJ, Adams DJ. Co-precipitation of DEAE-dextran coated SPIONs: how synthesis conditions affect particle properties, stem cell labelling and MR contrast. Contrast Media Mol Imaging. 2016;11:362-70.

26. Barrow M, Taylor A, Nieves DJ, Bogart LK, Mandal P, Collins CM, Moore LR, Chalmers JJ, Lévy R, Williams SR, et al. Tailoring the surface charge of 
dextran-based polymer coated SPIONs for modulated stem cell uptake and MRI contrast. Biomater Sci. 2015;3:608-16.

27. Barrow M, Taylor A, Murray P, Rosseinsky MJ, Adams DJ. Design considerations for the synthesis of polymer coated iron oxide nanoparticles for stem cell labelling and tracking using MRI. Chem Soc Rev. 2015;44:6733-48.

28. Ittrich $H$, Lange $C$, Tögel F, Zander AR, Dahnke H, Westenfelder C, Adam G, Nolte-Ernsting C. In vivo magnetic resonance imaging of iron oxidelabeled, arterially-injected mesenchymal stem cells in kidneys of rats with acute ischemic kidney injury: detection and monitoring at 3T. J Magn Reson Imaging. 2007;25:1179-91.

29. Papazova DA, Oosterhuis NR, Gremmels H, van Koppen A, Joles JA, Verhaar MC. Cell-based therapies for experimental chronic kidney disease: a systematic review and meta-analysis. Dis Model Mech. 2015;8:281-93.

30. Schrepfer S, Deuse T, Reichenspurner H, Fischbein MP, Robbins RC, Pelletier MP. Stem cell transplantation: the lung barrier. Transplant Proc. 2007;39:573-6.

31. Lee RH, Pulin AA, Seo MJ, Kota DJ, Ylostalo J, Larson BL, Semprun-Prieto L, Delafontaine P, Prockop DJ. Intravenous hMSCs improve myocardial infarction in mice because cells embolized in lung are activated to secrete the anti-inflammatory protein TSG-6. Cell Stem Cell. 2009;5:54-63.

32. Santeramo I, Perez ZH, Illera A, Taylor A, Kenny S, Murray P, Wilm B, Gretz N. Human kidney-derived cells ameliorate acute kidney injury without engrafting into renal tissue. Stem Cells Transl Med. 2017;6(5):1373-84.

33. Leibacher J, Henschler R. Biodistribution, migration and homing of systemically applied mesenchymal stem/stromal cells. Stem Cell Res Ther. 2016;7:7.

34. Eggenhofer E, Benseler V, Kroemer A, Popp FC, Geissler EK, Schlitt HJ, Baan CC, Dahlke MH, Hoogduijn MJ. Mesenchymal stem cells are short-lived and do not migrate beyond the lungs after intravenous infusion. Front Immunol. 2012;3:297.

35. Fischer UM, Harting MT, Jimenez F, Monzon-Posadas WO, Xue H, Savitz SI. Pulmonary passage is a major obstacle for intravenous stem cell delivery: the pulmonary first-pass effect. Stem Cells Dev. 2009;18:683-92.

36. Morigi M, Imberti B, Zoja C, Corna D, Tomasoni S, Abbate M, Rottoli D, Angioletti S, Benigni A, Perico N, et al. Mesenchymal stem cells are renotropic, helping to repair the kidney and improve function in acute renal failure. J Am Soc Nephrol. 2004;15:1794-804.

37. Zhuo W, Liao L, Fu Y, Xu T, Wu W, Yang S, Tan J. Efficiency of endovenous versus arterial administration of mesenchymal stem cells for ischemiareperfusion-induced renal dysfunction in rats. Transplant Proc. 2013;45: 503-10.

38. Combination Stem Cell (MESENDO) Therapy for Utilization and Rescue of Infarcted Myocardium. 2011:https://clinicaltrials.gov Identifier No NCT00548613.

39. Walter DH, Krankenberg H, Balzer JO, Kalka C, Baumgartner I, Schluter M, Tonn T, Seeger F, Dimmeler S, Lindhoff-Last E, et al. Intraarterial administration of bone marrow mononuclear cells in patients with critical limb ischemia: a randomized-start, placebo-controlled pilot trial (PROVASA). Circ Cardiovasc Interv. 2011:4:26-37.

40. Squillaro T, Peluso G, Galderisi U. Clinical trials with mesenchymal stem cells: an update. Cell Transplant. 2016;25:829-48.

41. Autologous neo-kidney augment (NKA) in patients with type 2 diabetes and chronic kidney disease (CKD). 2017:https://clinicaltrials.gov Identifier No NCT02525263.

42. Safety of autologous M2 macrophage in treatment of non-acute stroke patients. 2016:https://clinicaltrials.gov Identifier No NCT01845350.

43. Workman P, Aboagye EO, Balkwill F, Balmain A, Bruder G, Chaplin DJ, Double JA, Everitt J, Farningham DAH, Glennie MJ, et al. Guidelines for the welfare and use of animals in cancer research. Br J Cancer. 2010;102:1555-77.

44. Fuente Mora C, Ranghini E, Bruno S, Bussolati B, Camussi G, Wilm B, Edgar D, Kenny SE, Murray P. Differentiation of podocyte and proximal tubule-like cells from a mouse kidney-derived stem cell line. Stem Cells Dev. 2012;21:296-307.

45. Taylor A, Herrmann A, Moss D, See V, Davies K, Williams SR, Murray P. Assessing the efficacy of nano- and micro-sized magnetic particles as contrast agents for MRI cell tracking. PLoS One. 2014;9:e100259.

46. Kutner $\mathrm{RH}$, Zhang $\mathrm{XY}$, Reiser J. Production, concentration and titration of pseudotyped HIV-1-based lentiviral vectors. Nat Protoc. 2009;4:495-505.

47. Nikoobakht B, El-Sayed MA. Preparation and growth mechanism of gold nanorods (NRs) using seed-mediated growth method. Chem Materials. 2003;15:1957-62

48. Wälchli T, Mateos JM, Weinman O, Babic D, Regli L, Hoerstrup SP, Gerhardt $\mathrm{H}$, Schwab ME, Vogel J. Quantitative assessment of angiogenesis, perfused blood vessels and endothelial tip cells in the postnatal mouse brain. Nat Protocols. 2015;10:53-74.

49. Sharkey J, Starkey Lewis PJ, Barrow M, Alwahsh SM, Noble J, Livingstone E, Lennen RJ, Jansen MA, Carrion JG, Liptrott N, et al. Functionalized superparamagnetic iron oxide nanoparticles provide highly efficient ironlabeling in macrophages for magnetic resonance-based detection in vivo. Cytotherapy. 2017;19:555-69.

50. Balian G, Wang GJ, Diduch D, Hahn C. Pluripotential bone marrow cell line and methods of using the same: Google Patents; 2000. patent US6082364 (A). https://patents.google.com/patent/US6082364A/en.

51. Xing L, Cui R, Peng L, Ma J, Chen X, Xie RJ, Li B. Mesenchymal stem cells, not conditioned medium, contribute to kidney repair after ischemiareperfusion injury. Stem Cell Res Ther. 2014;5:101.

52. Sagrinati C, Netti GS, Mazzinghi B, Lazzeri E, Liotta F, Frosali F, Ronconi $E_{\text {, }}$ Meini C, Gacci M, Squecco R, et al. Isolation and characterization of multipotent progenitor cells from the Bowman's capsule of adult human kidneys. J Am Soc Nephrol. 2006;17:2443-56.

53. Schenk S, Mal N, Finan A, Zhang M, Kiedrowski M, Popovic Z. Monocyte chemotactic protein-3 is a myocardial MSC homing factor. Stem Cells. 2007; 25:245-51.

54. Sharkey J, Scarfe L, Santeramo I, Garcia-Finana M, Park BK, Poptani H, Wilm B, Taylor A, Murray P. Imaging technologies for monitoring the safety, efficacy and mechanisms of action of cell-based regenerative medicine therapies in models of kidney disease. Eur J Pharmacol. 2016;790:74-82.

55. Lin P, Correa D, Kean TJ, Awadallah A, Dennis JE, Caplan Al. Serial transplantation and long-term engraftment of intra-arterially delivered clonally derived mesenchymal stem cells to injured bone marrow. Mol Ther. 2014;22:160-8

56. Galleu A, Riffo-Vasquez Y, Trento C, Lomas C, Dolcetti L, Cheung TS, von Bonin M, Barbieri L, Halai K, Ward S, et al. Apoptosis in mesenchymal stromal cells induces in vivo recipient-mediated immunomodulation. Sc Transl Med. 2017;9(416):eaam7828.

57. Wang Y, Wang YP, Zheng G, Lee WWS, Ouyang L, Chang DHH, Mahajan D, Coombs J, Wang YM, Alexander SI, Harris DCH. Ex vivo programmed macrophages ameliorate experimental chronic inflammatory renal disease. Kidney Int. 2007;72:290-9.

58. Geng Y, Zhang L, Fu B, Zhang J, Hong Q, Hu J, Li D, Luo C, Cui S, Zhu F, Chen $X$. Mesenchymal stem cells ameliorate rhabdomyolysis-induced acute kidney injury via the activation of M2 macrophages. Stem Cell Res Ther. 2014;5:80

59. Dou H, Destache CJ, Morehead JR, Mosley RL, Boska MD, Kingsley J, Gorantla S, Poluektova L, Nelson JA, Chaubal M, et al. Development of a macrophage-based nanoparticle platform for antiretroviral drug delivery. Blood. 2006:108:2827-35.

60. Barrett DM, Seif AE, Carpenito C, Strong EP, June CH, Grupp SA, Reid GSD. Bioluminescent tracking of human and mouse acute lymphoblastic leukemia reveals potent immunogenicity of luciferase in some preclinical models of leukemia. Blood. 2010;116:2140.

61. Diduch DR, Coe MR, Joyner C, Owen ME, Balian G. Two cell lines from bone marrow that differ in terms of collagen synthesis, osteogenic characteristics, and matrix mineralization. J Bone Joint Surg Am. 1993;75:92-105.

62. Juffroy O, Noel D, Delanoye A, Viltart O, Wolowczuk I, Verwaerde C. Subcutaneous graft of D1 mouse mesenchymal stem cells leads to the formation of a bone-like structure. Differentiation. 2009;78:223-31.

63. Lye KL, Nordin N, Vidyadaran S, Thilakavathy K. Mesenchymal stem cells: from stem cells to sarcomas. Cell Biol Int. 2016;40:610-8.

64. Mohseny AB, Hogendoorn PC. Concise review: mesenchymal tumors: when stem cells go mad. Stem Cells. 2011;29:397-403.

65. Karp JM, Leng Teo GS. Mesenchymal stem cell homing: the devil is in the details. Cell Stem Cell. 2009;4(3):206-16.

66. Xu XC, Goodman J, Sasaki H, Lowell J, Mohanakumar T. Activation of natural killer cells and macrophages by porcine endothelial cells augments specific T-cell xenoresponse. Am J Transplant. 2002;2:314-22.

67. Barcia RN, Santos JM, Filipe M, Teixeira M, Martins JP, Almeida J, Agua-Doce A, Almeida SC, Varela A, Pohl S, et al. What makes umbilical cord tissuederived mesenchymal stromal cells superior immunomodulators when compared to bone marrow derived mesenchymal stromal cells? Stem Cells Int. 2015;2015:583984.

68. Gao F, Chiu SM, Motan DA, Zhang Z, Chen L, Ji HL, Tse HF, Fu QL, Lian Q. Mesenchymal stem cells and immunomodulation: current status and future prospects. Cell Death Dis. 2016;7:e2062. 